\title{
PELATIHAN KARAWITAN DAN TARI GAYA MINANG PADA SANGGAR SENI SAYUK RUKUN DUKUH GIRIMULYA DESA TIBAYAN KECAMATAN JATINOM KABUPATEN KLATEN
}

\author{
Teti Darlenis \\ Jurusan Etnomusikologi \\ Fakultas Seni Pertunjukan ISI Surakarta \\ Email: tetibahenol@gmail.com \\ Iwan Budi Santoso \\ Jurusan Etnomusikologi \\ Fakultas Seni Pertunjukan ISI Surakarta \\ Email: iwan_onone@yahoo.com
}

\begin{abstract}
Abstra
Bangsa Indonesia dengan beragam kekayaan seni dan budaya yang ditemukan di berbagai pulau dari Sabang hingga Merauke adalah aset nasional yang luar biasa. Inilah identitas masing-masing daerah yang merupakan bagian dari Bangsa Indonesia. Stabilitas identitas daerah di Indonesia dibutuhkan untuk menangkal derasnya arus budaya asing di era globalisasi yang terkadang memiliki bagian-bagian yang tidak sesuai dengan kepribadian bangsa. Kegiatan Pengabdian Masyarakat adalah bagian dari cara untuk memperkuat identitas nasional di masyarakat. Musik dan tarian adalah bagian dari seni yang memiliki peran yang penting dalam pengembangan karakter kehidupan masyarakat. Keduanya adalah bentuk kekayaan budaya. Karawitan dan tarian yang tumbuh dan berkembang di Indonesia adalah kekayaan yang beragam, dan ada yang sesuai dengan budaya masyarakatnya. Untuk memperkuat dan menerapkan perlawanan terhadap derasnya budaya asing, peran Pengabdian Masyarakat dalam bentuk pelatihan musik dalam tari gaya Minang untuk masyarakat Jawa adalah kegiatan positif. Manfaat kegiatan Pengabdian Masyarakat pada akhirnya mampu mendominasi dan memperkaya kosakata seni antar daerah. Dengan demikian akan berdampak pada pengalaman dan pengetahuan masyarakat lain untuk belajar tentang budaya bangsa.
\end{abstract}

Kata kunci : musik, tarian, budaya, identitas.

\begin{abstract}
The Indonesian nation with its diverse artistic and cultural richness found on various islands from Sabang to Merauke is an extraordinary national asset. This is the identity of each region which is part of the Indonesian Nation. The stability of regional identity in Indonesia is needed to ward off the swift flow of foreign culture in the era of globalization, which sometimes has parts that are incompatible with the nation's personality. Community Service Activities are part of ways to strengthen national identity in the community. Music and dance are parts of art that have an important role in developing the character of people's lives. Both are forms of cultural wealth. Karawitan and dances that grow and develop in Indonesia are diverse in wealth, and some are in accordance with the culture of the people. To strengthen and implement resistance to the swift
\end{abstract}




\section{Abdi Seni Jurnal Pengabdian Kepada Masyarakat}

foreign culture, the role of Community Service in the form of music training in Minang style dance for Javanese people is a positive activity. The benefits of Community Service activities are ultimately able to dominate and enrich art vocabulary between regions. Thus it will have an impact on the experience and knowledge of other communities to learn about the nation's culture.

Keywords: music, dance, culture, identity.

\section{PENDAHULUAN}

Keberadaan sanggar seni di suatu daerah menunjukkan bahwa keinginan untuk melestarikan suatu jenis kesenian di daerah tersebut masih ada. Sanggar-sanggar seni di suatu daerah akan berjalan dan berkembang dengan baik apabila mendapat dukungan dari masyarakat sekitarnya. Salah satu bentuk dukungan dari masyarakat tersebut yaitu dengan mengizinkan atau mengikutkan anak-anak mereka dalam kegiatan sanggar seni yang terdapat di daerah tempat tinggalnya. Hal ini akan lebih baik lagi apabila keberadaan sanggar seni tersebut juga didukung oleh pemerintahan setempat, baik mulai dari Ketua R.T. Ketua R.W., maupun aparat desa setempat. Dengan cara yang demikian, maka dipastikan keberadaan sanggar seni akan bertahan hidup dan berjalan dengan baik dalam melaksanakan tugas sebagai pelestari kesenian di daerah.

Sanggar Seni "Sayuk Rukun" yang berlokasi di Dukuh Girimulya, Desa Tibayan, Kecamatan Jatinom, Kabupaten Klaten, adalah sebuah sanggar seni yang bertahan hidup berkat dukungan dari masyarakat sekitarnya serta mendapat apresiasi yang baik dari pemerintah desa setempat. Sanggar Seni “Sayuk Rukun” terbentuk pada awal tahun 2015 atas prakarsa seorang tokoh masyarakat setempat yang bernama Bapak Muhammad Ansori yang sekaligus menjadi pembina, serta Bapak Sugiran yang kemudian menjadi pelatih kelompok karawitan.

Peserta latihan dalam Sanggar Seni "Sayuk Rukun" tersebut sebagian besar adalah anak-anak yang masih belajar di bangku Sekolah Dasar (SD) dan Sekolah Menengah Pertama (SMP). Sanggar Seni "Sayuk Rukun" bergerak dalam kegiatan pelatihan seni, baik karawitan, tari, maupun berbagai seni vokal. Kegiatan yang sangat menonjol dalam Sanggar Seni "Sayuk Rukun" adalah pelatihan karawitan anak-anak. Kelompok karawitan yang tergabung dalam Sanggar Seni “Sayuk Rukun” sudah beberapa kali menerima undangan di luar Desa Tibayan untuk pentas dalam berbagai keperluan, seperti pentas dalam acara pembukaan pengajian akbar di Gedung Sekretariat Muhammadiyah Kecamatan Jatinom, pentas dalam acara pembukaan perayaan "Yoqowiyu" di Kecamatan Jatinom, terlibat dalam pentas kolosal "Gora Swara" bersama seniman-seniman se-Kabupaten Klaten di lereng Merapi, dan mengisi acara bulanan di kantor KPU Kabupaten Klaten.

Kondisi berbeda dialami peserta latihan tari karena belum banyak tampil di luar lingkungan sanggar. Akan tetapi, pertunjukan tari dipentaskan secara berkala di dalam sanggar sebagai evaluasi terhadap kemampuan para peserta latihan. Selain belajar karawitan Jawa, para peserta latihan di Sanggar Seni "Sayuk Rukun" juga berkeinginan untuk mempalajari karawitan dari daerah lain, salah satunya adalah karawitan Minang. Keinginan untuk mempelajari karawitan dan tari gaya Minang ini dimaksudkan untuk memperkaya wawasan anakanak dalam dunia karawitan, baik pola-pola tabuhan instrumen karawitan Minang maupun lagu-lagu vokal Minang.

Penguasaan pola-pola tabuhan instrumen karawitan dan tari gaya Minang serta lagu-lagu vokal dalam karawitan dan tari gaya Minang ini akan digunakan untuk persiapan dalam mengikuti pentas kolosal “Gora Swara” bersama seniman-seniman seKabupaten Klaten yang diadakan setiap tahun di lereng Merapi. Dalam pentas tersebut setiap 
kelompok karawitan diberi kebebasan untuk menampilkan kreatifitasnya yang berupa komposisi musik. Komposisi musik tersebut kemudian digabung dengan penampilan dari kelompok karawitan yang lain sehingga terbetuk satu kesatuan komposisi musik yang diberi judul "Gora Swara".

Penguasaan pola-pola tabuhan instrumen karawitan Minang, serta lagu-lagu vokal dalam karawitan Minang yang dipadukan dengan karawitan Jawa, maka akan memberi warna komposisi musik baru bagi penampilan kelompok karawitan dari Sanggar Seni "Sayuk Rukun”. Dalam rangka memenuhi keinginan untuk menguasai pola-pola tabuhan instrumen serta lagu-lagu vokal dalam karawitan Minang seperti yang telah disebut di atas, maka saya selaku pelatih musik yang merupakan pengajar mata kuliah Karawitan Minang di Institut Seni Indonesia (ISI) Surakarta telah beberapa kali di undang untuk melatih karawitan Minang pada Sanggar Seni “Sayuk Rukun”. Dalam kesempatan tersebut diberikan contoh pola- pola tabuhan instrument talempong pacik, pola tabuhan gandang tambua (gendang), serta beberapa contoh lagu vokal karawitan Minang.

Keinginan untuk belajar karawitan dan tari gaya Minang oleh anak-anak yang tergabung dalam Sanggar Seni "Sayuk Rukun" ini semakin bersemangat setelah mereka merasakan dan berlatih pola- pola tabuhan instrumen talempong pacik, pola tabuhan gandang tambua, serta beberapa contoh lagu vokal Minang. Mereka melakukannya dengan rasa senang dan antusias. Oleh sebab itu Bapak Sugiran selaku pelatih karawitan di Sanggar Seni "Sayuk Rukun" meminta kepada penulis untuk melatih karawitan dan tari gaya Minang kepada kelompok karawitan anak yang tergabung dalam Sanggar Seni “Sayuk Rukun" secara rutin.

Proses adaptasi dari kebiasaan berlatih Karawitan Jawa yang kemudian berlatih karawitan dan tari gaya Minang bagi anak-anak yang tergabung dalam Sanggar Seni "Sayuk Rukun tidak menemui kesulitan. Hal ini tidak terlepas dari kreativitas dari Bapak Sugiran sebagai pelatih karawitan pada kelompok karawitan di Sanggar Seni "Sayuk
Rukun”. Dalam latihan karawitan Jawa sebelumnya, beliau banyak mengaransemen lagu-lagu nasional yang menggunakan nada diatonis seperti Indonesia Raya, Garuda Pancasila, Benderaku, Sorak Bergembira, serta lagu-lagu Indonesia yang lain seperti Lihat Kebunku, dan Burung Kakak Tua yang ditransformasikan ke dalam sajian gending karawitan Jawa dengan cara dibuatkan notasi kepatihan. Lagulagu berbahasa Indonesia yang disajikan dengan gamelan Jawa dalam bentuk lancaran ini ternyata memudahkan bagi anak-anak dalam mengikuti latihan karawitan meskipun nada-nada lagu vokalnya merupakan campuran antara nada-nada pentatonis dan nada-nada diatonis.

Pengalaman menyajikan lagu-lagu yang demikian, memudahkan anak-anak dalam menyajikan lagu vokal dalam karawitan Minang. Hal ini disebabkan nada-nada lagu vokal dalam Karawitan Minang juga merupakan campuran antara nada-nada pentatonis dan nada-nada diatonis. Mereka tidak mengalami kesulitan ketika belajar memainkan beberapa instrumen karawitan Minang, karena ketika belajar karawitan Jawa mereka sudah terbiasa memainkan berbagai permainan imbal bonang dan saron barung, serta jalinan permainan instrumen terbang.

Mengingat peserta latihan karawitan dalam Sanggar Seni “Sayuk Rukun” Dukuh Girimulya ini juga terdapat beberapa orang penari, maka dalam program pelatihan inijuga diberikan pola-pola gerak tari Minang. Pola-pola gerak tari Minang tersebut disesuaikan dengan materi lagu musik (gending) Minang yang digunakan sebagai materi latihan. Dengan demikian dalam proses latihan ini tercipta keakraban yang sangat baik dari para anggota yang tergabung dalam Sanggar Seni "Sayuk Rukun" Dukuh Girimulya.

Keinginan dari anggota yang tergabung dalam Sanggar Seni "Sayuk Rukun" untuk mempelajari Karawitan Minang dan pola gerakgerak tari Minang mendapat sambutan yang menggembirakan, baik warga masyarakat Dukuh Girimulya maupun pejabat tingkat Desa Tibayan. Hal ini menunjukkan bahwa belajar karawitan dan tari 


\section{Abdi Seni Jurnal Pengabdian Kepada Masyarakat}

tidak hanya karawitan dan tari Jawa saja, tetapi juga harus mengenal dan ikut merasa memiliki berbagai jenis karawitan dan tari yang ada di Indonesia, salah satunya adalah karawitan dan tari Minang.

Setelah peserta latihan menguasai berbagai pola tabuhan instrumen dan lagu-lagu vokal dalam Karawitan Minang, serta pola gerak-gerak tari Minang, diharapkan mereka pada setiap pementasannya dapat mengkolaborasikan antara karawitan Jawa dengan karawitan Minang dengan latar belakang pola gerak-gerak tari Jawa dan Minang. Dengan demikian, keberadaan kelompok karawitan dan tari dalam Sanggar Seni "Sayuk Rukun" Dukuh Girimulya ini akan selalu menampilkan suasana yang berbeda pada setiap penampilannya. Hal ini dapat menarik minat masyarakat untuk selalu menggunakan jasanya dalam berbagai keperluan.

Anggota kelompok karawitan dan tari yang tergabung dalam Sanggar Seni "Sayuk Rukun" di Dukuh Girimulya, Desa Tibayan, Kecamatan Jatinom, Kabupaten Klaten, sebagian besar terdiri dari anak-anak yang masih belajar di bangku Sekolah Dasar dan Sekolah Menengah Pertama. Dalam memainkan instrumen gamelan Jawa, mereka sudah mempunyai kemampuan menabuh yang cukup baik, terutama tempo sajian dan kekompakan dalam menyajikan gending. Demikian juga para penyaji vokal yang sudah peka terhadap tempo sajian dan kekompakan dalammenyuarakan lagu vokal secara bersama-sama. Begitu juga dengan para peserta latihan tari yang sudah mampu menarikan beberapa tari Jawa dengan baik.

Kemampuan yang telah dimiliki peserta pelatihan dalam memainkan tempo serta kekompakan dalam bermain karawitan Jawa seperti yang telah disebut di atas, memudahkan mereka ketika menerima materipelatihan tentang pola-pola tabuhan instrumen karawitan Minang serta lagu-lagu vokal Minang. Faktor lain yang memudahkan dalam pemberian meteri latihan adalah rasa senang mereka terhadap hal-hal baru. Belajar karawitan Minang bagi mereka adalah sebuah pengalaman baru yang dapat memperluas wawasan di bidang karawitan. Selain itu mereka merasa senang dapat berkumpul dengan teman-teman mereka dalam kegiatan yang positif. Kegiatan latihan karawitan dijadikan sebagai ajang untuk membangun kekompakan dan kerukunan sesama teman bermain. Dengan modal dasar yang demikian, maka pelatihan tentang polapola tabuhan instrumen karawitan Minang serta lagu-lagu vokal Minang akan diterima dengan senang hati, sehingga materi-materi latihan yang diberikan akan mudah dikuasainya.

Kendala yang dihadapi oleh para anggota kelompok karawitan yang tergabung dalam Sanggar Seni "Sayuk Rukun" dalam mengikuti latihan karawitan Minang adalah masalah cara membaca notasi. Hal ini disebabkan sejak awal tidak dikenalkan dengan cara membaca notasi. Kendala lain yang dihadapi oleh kelompok karawitan dan tari dalam Sanggar Seni "Sayuk Rukun" adalah masalah waktu atau jadwal latihan. Hal ini disebabkan para peserta latihan yang sebagian besar adalah anakanak yang masih sekolah, sehingga jadwal latihan diusahakan tidak mengganggu kegiatan belajar sekolah mereka.

Mengingat anggota kelompok karawitan dan tariyang tergabung dalam Sanggar Seni "Sayuk Rukun" sangat antusias untuk belajar karawitan, maka hal ini patut mendapat perhatian dari lembagalembaga kesenian yang berkewajiban untuk menjaga agar kehidupan kesenian pada umumnya dan karawitan khususnya tetap berkembang secara wajar. Kita wajib bersyukur, di tengah maraknya para anak muda yang beramai-ramai meninggalkan kesenian tradisi, namun masih ada anak-anak usia Sekolah Dasar dan Sekolah Menengah Pertama yang mau bergabung dan berlatih dalam kelompok karawitan dan tari dengan tujuan untuk melestarikan kesenian yang pernah mengisi kehidupan di kampung mereka.

Hal yang sangat dibutuhkan pada saat ini adalah kehadiran tenaga pelatih karawitan dan tari yang dapat melatih karawitan dan tari Minang dengan benar. Oleh sebab itu kehadiran tenaga pelatih dari lembaga yang berkecimpung di bidang kesenian 
seperti ISI Surakarta sangat diharapkan, sehingga dapat menarik minat masyarakat sekitarnya untuk senang berlatih karawitan dan tari. Selain itu, dengan bergabungnya pengajar karawitan dari ISI Surakarta dengan kelompok karawitan dan tari di masyarakat, maka akan dapat menjalin kerjasama yang baik antara ISI Surakarta dengan masyarakat. Bagi ISI Surakarta, kesempatan ini menjadi wadah untuk mengaplikasikan ilmu-ilmu yang terkait dengan pembelajaran karawitan dan tari kepada masyarakat. Sedangkan bagi masyarakat dan peserta latihan, kegiatan ini menyediakan kesempatan untuk mempelajari dan mempraktekkan cara berkarawitan dan menari secara baik dan benar.

\section{MATERI DAN METODE}

Metode yang digunakan dalam pelatihan ini adalah dengan cara Trainer Penciptaan. Metode ini mencakup cara seorang tutor menularkan pengetahuan dan keterampilan seni karawitan, dengan menggunakan teknik drill, demonstrasi, dan dialog. Pelatihan di bidang vokal menekankan bagaimana teknik menyuarakan lagu vokal yang benar dan latihan membaca notasi lagu vokal secara bersama (koor), serta melatih kekompakan dalam menyajikan lagu vokal. Selain itu, pelatihan vokal ini juga melatih peserta untuk dapat menyanyikan lagu secara tunggal. Mengingat notasi lagulagu vokal Minang ini ditulis dengan menggunakan notasi sol mi sa si ( do re mi fa sol la si do), maka hal ini akan memudahkan para peserta latihan dalam membaca notasi lagu-lagu vokal Minang, karena mereka sebelumnya sudah terbiasa membaca notasi sol mi sa si yang ditransfer ke dalam gamelan Jawa.

Bentuk pelatihan yang digunakan dalam program ini, pertama-tama peserta latihan disuruh memperhatikan contoh-contoh yang diberikan oleh pelatih, baik pola-pola tabuhan instrumen maupun contoh-contoh lagu vokal Minang. Langkah selanjutnya adalah peserta latihan disuruh menyajikan pola-pola tabuhan instrumen secara bersama-sama. Dalam praktek bersama ini pelatih membetulkan apabila peserta latihan belum dapat menyajikan secara benar. Praktek bersama tersebut terus diulang-ulang sampai semua peserta dapat menyajikan pola-pola tabuhan inastrumen. Latihan lagu vokal yang dilakukan dengan model yang sama. Model pelatihan seperti ini diharapkan mampu mambantu para peserta latihan dalam belajar menyajikan pola-pola tabuhan instrumen karawitan Minang serta lagu-lagu vokal Minang secara benar dan baik.

Setelah mereka dapat memainkan atau menabuh pola pola tabuhan instrument karawitan Minang serta menyajikan lagu-lagu vokal Minang secara benar dan baik, kemudian mereka diberikan materi bentuk lagu secara utuh. Adapun materi yang akan diajarkan dalam program pelatihan ini adalah "Dendang Musik Tari Piring" dan "Lagu Rumah Gadang”. Kedua materi ini digunakan sebagai aplikasi untuk melatih keterampilan menabuh dan menutup pada instrumen talempong pacik dan permainan gandang tambua (gendang) dengan tempo yang cepat, serta melatih kekompakan dalam menyajikan lagu vokal Minang.

Mengingat dalam program pelatihan di Sanggar Seni “Sayuk Rukun” Dukuh Girimulya tersebut juga terdapat anggota yang belajar tentang tari, maka mereka juga diberi pelatihan pola-pola gerak tari Minang yang sesuai dengan materi lagu musik yang digunakan dalam pelatihan ini, yaitu "Dendang Musik Tari Piring". Dengan melibatkan para pengrawit dan penari dalam program pelatihan, maka hal ini akan menambah keakraban dan kegembiraan bagi para anggota yang tergabung dalam Sanggar Seni “Sayuk Rukun” Dukuh Girimulya.

\section{PEMBAHASAN}

Rangkaian pelaksanaan kegiatan pengabdian masyarakat (PKM) pada tahun 2019 diawali dengan kunjungan ke Sanggar Seni "Sayuk Rukun" Dukuh Girimulya, Desa Tibayan, Kecamatan Jatinom, Kabupaten Klaten. Selain 


\section{Abdi Seni Jurnal Pengabdian Kepada Masyarakat}

melakukan survei lokasi, kami juga memohon izin pelaksanaan kegiatan PKM kepada pimpinan sanggar dan kepala Desa Tibayan. Pada saat survei di Sanggar Seni Sayuk Rukun, kami juga melihat potensi dan bakat para murid dan/ atau warga yang sedang latihan. Dengan demikian, pada pelaksanaan program PKM kami tidak lagi mencari permasalahan dan kekurangan yang ada di Sanggar Sayuk Rukun. Seperti yang sudah diketahui permasalahan sejak survei, maka permasalahan dan kekurangan dapat diatasi dengan solusi materi kegiatan PKM disesuaikan dengan kebutuhan sanggar.

\section{Uraian Kegiatan Yang Telah Dilaksanakan}

Untuk mencapai target luaran yang maksimal, realisasi pelaksanaan kegiatan PKM diawali pada bulan Juni sampai dengan bulan Agustus 2019. Oleh karena awal bulan Juni bertepatan dengan hari raya Idul Fitri, maka kegiatan bisa dimulai minggu kedua. Dikarenakan Sanggar Sayuk Rukun pada bulan Agustus minggu kedua padat acara peringanan HUT RI ke-74, maka pelatihan karawitan dan tari gaya Minang dilakukan secara intens. Proses latihan karawitan dan tari gaya Minang diawali dengan pengenalan instrumen. Pengenalan insturmen musik karawitan Minang antara lain talempong pacik, gandhang tambua, tasa, gandhang kantindiak, sarunai, dan vokal. Dari beberapa instrumen yang kami perkenalkan tentu tidak langsung dimainkan bersama. Namun demikian, kami kenalkan dari instrumen yang mudah terlebih dahulu, misalnya talempong pacik.

Selanjutnya, peserta pelatihan kami kenalkan cara memainkan instrumen lain seperti yang sudah kami sampaikan di atas. Proses latihan berlangsung seperti yang direncanakan sejak awal. Peserta pelatihan yang umumnya masih anak usia $10 \mathrm{~s} / \mathrm{d} 15$ tahun, cukup mudah dalam menyerap dan merespon materi, baik materi musik maupun tari gaya Minang. Hal ini dikarenakan peserta pelatihan telah menguasai dasar-dasar musik karawitan Jawa, sehingga mereka cukup mudah merespon nada-nada karawitan Minang. Begitu juga peserta pelatihan yang sudah mempunyai kemampuan dasar tari gaya Jawa, mereka dapat beradaptasi dengan baik dalam mempraktekkan materi tari gaya Minang. Capaian dalam pelatihan karawitan Minang meliputi pengenalan instrumen, memainkan instrumen, serta memainkan komposisi lagu Minang. Demikian pula capaian dalam pelatihan tari gaya Minang, yaitu pengenalan gerak dasar sampai pola lantai tari gaya Minang. Akhir dari pelaksanaan kegiatan PKM di Sanggar "Sayuk Rukun" yang kami lakukan yaitu berupa sebuah pertunjukan karawitan dan tari gaya Minang.

\section{Kebaruan Bidang PKM}

Kelompok "Sayuk Rukun" Dukuh Girimulya, Desa Tibayan, Kecamatan Jatinom, Kabupaten Klaten, merupakan sanggar seni yang berlatih musik karawitan dengan instrumen gamelan Jawa. Kebaharuan dalam konteks ini adalah dalam hal materi pelatihan. Materi yang diberikan adalah musik karawitan dan tari gaya Minang. Pelatihan dengan materi berbeda kultur bagi para anggota kelompok "Sayuk Rukun", bermanfaat untuk menambah ilmu dan pengalaman baru bagi anakanak dalam memainkan instrumen dari etnis lain, khususnya praktik karawitan dan tari gaya Minang. Pada kesempatan inilah mereka dapat merasakan perbedaan pada proses belajar, berlatih, dan menempa pengetahuan sekaligus praktek kesenian dari kultur yang berbeda.

Proses kegiatan pelatihan materi karawitan dan tari gaya Minang diawali dengan pengenalan notasi, instrumen musik (talempong), bentuk dan gerak tari, serta pola lantai tari. Hal tersebut ditata dan disusun dengan metode yang sudah disiapkan pelatih. Setiap kali selesai pelatihan, para anggota sanggar diajak untuk melakukan evaluasi dan diskusi bersama. Selain pelatihan berkelompok, juga dilaksanakan latihan secara parsial, guna memberi penekanan pada persoalan yang dianggap rumit, misalnya pola tabuhan, peralihan irama, dan gerak tari yang merupakan pengetahuan dan pengalaman baru bagi peserta latihan. 


\section{Luaran Kegiatan}

Pengabdian pada masyarakat di kelompok "Sayuk Rukun" berbentuk pelatihan karawitan dan tari gaya Minang, bertujuan meningkatkan ketrampilan anak-anak peserta sanggar dengan materi yang berbeda dari yang biasa mereka pelajari sebelumnya. Biasanya anggota kelompok "Sayuk Rukun" berlatih gamelan dan tari Jawa, sedangkan pada pelatihan ini diberi materi karawitan dan tari gaya Minang. Pelatihan ini selain memberikan pengetahuan dan ketrampilan tentang karawitan dan tari gaya Minang, juga bertujuan untuk menambah pengetahuan budaya musik Nusantara. Dengan demikian luaran kegiatan ini adalah kemampuan yang bersifat praktik dan ilmu pengetahuan budaya musik Nusantara, khususnya ketrampilan bermain musik karawitan gaya Minang dan keterampilan tari gaya Minang dengan tingkat menengah. Berbekal sedikit ilmu yang diberikan, paling tidak menambah sedikit keterampilan siswa peserta latihan di bidang karawitan dan tari gaya Minang. Dengan kegiatan ini diharapkan ke depannya tertanam rasa cinta budaya Nusantara pada generasi penerus bangsa. Selain itu diharapkan di masa yang akan datang dapat menumbuhkembangkan ketertarikan mereka untuk dapat menekuni karawitan gaya lain yang ada di Nusantara. Kegiatan ini merupakan pemicu awal, serta diharapkan juga menjadi sebuah aktivitas dan kreativitas mandiri dalam kelompok "Sayuk Rukun" yang dapat diprogramkan secara berkelanjutan. Selain paparan kegiatan pelatihan di kelompok Sayuk Rukun, kegiatan PKM ini juga akan membuat luaran berupa artikel jurnal.

\section{Metode Pelaksanaan}

Untuk mencapai hasil yang maksimal dalam pelatihan karawitan dan tari gaya Minang, perlu didukung dengan metode yang tepat agar proses pelatihan bisa berjalan lancar sesusai harapan. Pemilihan metode dilakukan dengan mempertimbangkan situasi dan kesesuaian materi pelatihan. Oleh karena materi yang diajarkan memiliki perbedaan dengan materi kesenian pada kultur peserta didik, maka diperlukan metode yang tepat, agar tetap sesuai dengan kebiasaan pelatihan karawitan dan tari Jawa pada umumnya. Dengan metode yang benar, optimalisasi keberhasailan pelatihan karawitan dan tari gaya Minang dapat dicapai. Dalam konteks pelatihan karawitan dan tari gaya Minang, metode yang diterapkan mempertimbangkan hal-hal sebagai berikut : tujuan pelatihan, capaian yang akan diraih, materiyang disampaikan, dan tingkat kemampuan peserta.

Metode-metode yang diterapkan dalam pelatihan antara lain ; ceramah, demonstrasi, partisipasi, diskusi, dan drill. Kadar persentase penerapan dari masing-masing metode berbeda dan sangat variatif, dengan detailnya sebagai berikut :

a) Metode ceramah. Metode ini digunakan untuk menjelaskan garap musik karawitan dan tari gaya Minang secara umum. Materi ini meliputi tentang garap karawitan, instrumen, dan materi lagu gaya Minang. Sedangkan untuk materi pelatihan tari berisi penjelasan tentang materi gerak, bentuk gerak, dan volume gerak tari gaya Minang.

b) Metode demontrasi, yaitu contoh terapan dari materi yang disampaikan dalam penjelasan.

c) Metode partisipasi. Pada metode ini diperlukan peran aktif para peserta dalam memperhatikan dan menirukan penjelasan serta demontrasi dari pelatih yang memberikan materi.

d) Metode diskusi. Metode ini merupakan wadah tanya-jawab antara pelatih dan siswa pada saat penjelasan materi maupan demontrasi. Ketika jeda latihan, siswa juga diperkenankan untuk memperdalam materi dengan berdiskusi.

Pada pelaksanaan di lapangan, berbagai metode di atas dilaksanakan secara fleksibel. Meskipun demikian terkadang dalam setiap pertemuan tidak diakukan secara berurutan seperti pada uraian di atas. Hal ini mengingat situasi dan kondisi peserta didik anak-anak yang membutuhkan variasi metode dalam penyampaian setiap materi, serta mempertimbangkan berbagai permasalahan yang muncul pada saat proses latihan. 


\section{Abdi Seni Jurnal Pengabdian Kepada Masyarakat}

\section{DAFTAR PUSTAKA}

Ahimsa Putra, Heddy Shri. 2003. "Ethnoart: Fenomenologi Seni Untuk Indiginasi Seni”" dalam Jurnal Pengkajian \& Penciptaan Seni Dewa Ruci, Program Pendidikan Pasca-sarjana STSI Surakarta.

Arifin Adam, Boestanul. 1986. "Talempong Musik

Tradisi Minangkabau". Laporan Penelitian. Padangpanjang: Akademi Seni Karawitan.

Evans, James R. 1994. Berfikir Kreatif. Jakarta:

Bumi Aksara.

Hajizar, dkk. 1993. "Talempong Tradisional dinagari

Pitalah dan Bunga Tanjung”. Laporan

Penelitian. Padangpanjang: Akademi Seni Karawitan.

Hatoko, Dick.1994.Manusia dan Seni, Yogyakarta : Kanisius.
Joesoef Noesjirwan. 1979. Pembinaan Harga Diri Pada Anak dalam Perkembangan Anak dan Remaja.Jakarta: Departeman Pendidikan Kebudayaan Dirjen Pendidikan Tinggi Proyek Normalisasi Kehidupan Kampus.

Navis, A. A. 1986. Alam Terkembang Jadi Guru: Adat dan Kebudayaan Minangkabau. Jakarta: Grafitipers.

Sumardjo, Jakob. 2000. Filsafat Seni, Bandung: ITB.

Supanggah, R. 1983. "Pokok-pokok Pikiran Tentang Garap", Makalah disampaikan dalam diskusi jurusan Karawitan ASKI Surakarta.

(ed), 1995. Etnomusikologi. Yogyakarta: Yayasan Bentang Budaya,

Timpe, Dale, (ed). 1992. Kreativitas. Jakarta: Gramedia. 